\title{
Los museos como factor de integración social del arte en la comunidad. La experiencia del Voluntariado cultural de mayores
}

\author{
Museums as a factor for the social integration of art in the community. \\ The experience of cultural volunteering by members \\ of the senior community
}

Luz María Gilabert GonZÁlez

Universidad Católica San Antonio de Murcia, España

lmgilabert@ucam.edu

Xavier LORENTE GUERRERO

Universidad Católica San Antonio de Murcia, España

xlorente@ucam.edu

Recibido: $29 / 05 / 2015$

Revisado: 01/06/2015

Aceptado: 02/10/2015

Disponible on line: 20/01/2016

\begin{abstract}
Resumen
Tras abordar la revisión de los museos como instituciones culturales encargadas de conservar la memoria cultural y su evolución a lo largo del tiempo, el artículo describe la práctica cultural que se está produciendo en el entorno español para realizar la difusión del arte, su reproducción y la transmisión de cultura, la historia y la identidad y el papel primordial que están desempeñando paulatinamente las personas mayores en una sociedad española cada vez más envejecida. Estas nuevas actividades de fortalecimiento social, a partir del voluntariado de las personas mayores, están relacionadas con la «generatividad» (potencialidad de una generación) que, por este medio, la persona y los grupos sociales adquieren nuevas competencias, lo que permite hacer más fuerte a una sociedad para todas las edades. Nunca, en la historia del Trabajo Social, han existido tantas personas mayores dispuestas a participar activa y comunitariamente y nunca ha pasado tan desapercibido para tantos agentes sociales un movimiento social de estas características.
\end{abstract}

Palabras clave: empoderamiento, «generatividad», personas mayores, museo, voluntariado.

\begin{abstract}
After considering museums as cultural institutions responsible for preserving cultural memory and its evolution over time, this article describes the cultural practices within our society that are aimed at disseminating art and at reproducing and transmitting culture, history and identity. Further, it considers the key role that older people are steadily assuming in Spain's ageing society. New social-empowerment activities based on volunteering by the elderly are linked to generativity because the individual and social groups acquire new skills through those activities, thereby strengthening a society for all ages. Never in the history of social work have so many older people been prepared to participate actively at the community level, and never has a social movement with these features gone so unnoticed by so many social agents.
\end{abstract}

Keywords: empowerment, generativity, elderly persons, museum, volunteering.

Referencia normalizada: Gilabert González, L. M., y Lorente Guerrero, X. (2016): «Los museos como factor de integración social del arte en la comunidad. La experiencia del Voluntariado cultural de mayores:. Cuadernos de Trabajo Social, 29(1): 83-93.

Sumario: Introducción. 1. Museos, cultura e identidad: reflexión histórica. 2. El Voluntariado cultural de mayores. Una experiencia consolidada en nuestro territorio. 3. La pedagogía de la experiencia. La «generatividad» como elemento vital. 4. El Trabajo Social y la «generatividad» como elementos de trabajo conjunto. 5. Transformación de la realidad a principios del siglo XXI. 6. Referencias bibliográficas. 


\section{Introducción}

Desde hace unas décadas se ha experimentado un gran cambio en el museo, fruto entre otros movimientos, de la democratización cultural. Este concepto se ha definido como la difusión de los beneficios de la cultura al conjunto de la población. Es decir, proporcionar conocimientos culturales y hacer que toda la sociedad sea partícipe en todos los ámbitos y sectores que, hasta ese momento, sólo estaban al alcance de los estatus más elitistas.

De hecho, la democratización de la cultura ha supuesto un paso adelante, ya que ha posibilitado el acceso a la cultura de toda la población y, al mismo tiempo, ha favorecido el control y el poder para su manipulación dentro de una sociedad en democracia y que a menudo obedece a estrategias de integración para generar grupos de pertenencia o de identificación con modelos dominantes. Por lo tanto, la práctica de la democracia cultural consiste en asegurar a personas, grupos, asociaciones, pueblos y naciones los instrumentos necesarios para desarrollar su vida cultural con libertad, responsabilidad y autonomía.

La democracia cultural entiende la cultura como participación abierta a todos, con el fin de potenciar los procesos creativos que se basan en la libre expresión. Además, intenta partir de la vivencia personal que genera la construcción de la identidad y que, al interaccionar con la sociedad, genera movimientos culturales de base. Por esa razón la democracia cultural comporta hoy un grado de revolución en el mundo de la cultura.

Esta transformación implicó un nuevo papel del museo como agente de integración social y, por ello, han sido varios los organismos y las publicaciones que se han hecho eco recientemente de esta misión de la institución museística. Basta citar como ejemplo, el Día Internacional del Museo de 2008, con el lema «Los museos, agentes del cambio social y el desarrollo»; el XVII Congreso Nacional de Amigos de los Museos; y la publicación del número 28 de la revista Amigos de los Museos. Todos ellos tenían como objetivo analizar el museo como instrumento de integración social en la actualidad y donde exprimir toda una temática social con las diferentes comunidades (Imagen 1).

En este artículo tratamos de acercarnos a este fenómeno, partiendo de una reflexión teórica sobre la relación histórica entre el museo y la in-
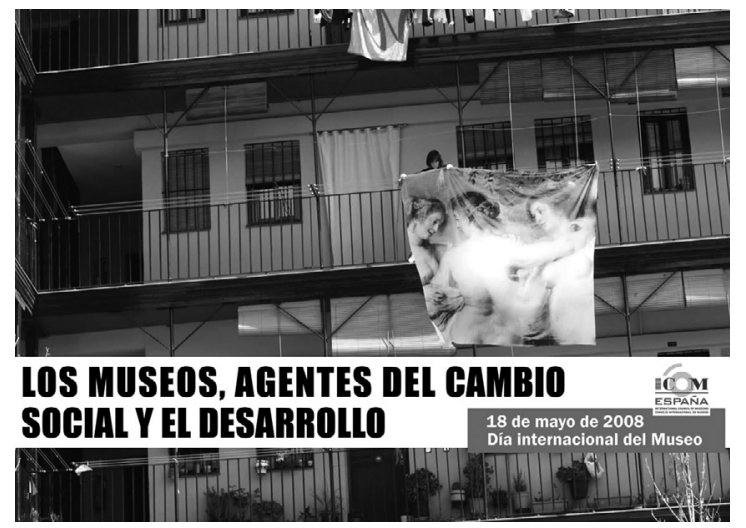

Imagen 1. Cartel del Día Internacional de los Museos de 2008.

Fuente: www.icom-ce.org.

tegración social, para después analizar uno de los casos más claros de esa acción comunitaria en los museos: el Voluntariado Cultural de Mayores.

\section{Museos, cultura e identidad: reflexión his- tórica}

El museo es una institución cultural consagrada por la propia historia que goza de un enorme prestigio y popularidad en el presente, como demuestra su imparable extensión por grandes ciudades y pequeñas poblaciones de todo el mundo. De hecho, tanto las administraciones públicas como los organismos privados luchan hoy por construir nuevos espacios museísticos que están convirtiendo al museo en la más exitosa de las organizaciones culturales contemporáneas. Pero, desde su origen, las constantes transformaciones de la sociedad han obligado a un esfuerzo continuo de adaptación y a tener que responder a las exigencias de cada época evolucionando a la luz de nuevos conceptos y valores.

La explicación del fenómeno museológico es el resultado de un entramado de factores de diversa naturaleza, especialmente de carácter político, económico y cultural, que confluyen en un mismo contexto social alrededor del cual se asienta la institución, y cuyas características afectan directamente a su propio desarrollo histórico. El museo en su inmovilidad aparente es una entidad viva que a lo largo de los siglos ha demostrado ser capaz de estar en constante renovación, adecuándose a los movimientos sociales, y ocupar un lugar prioritario en la historia cultural de las civilizaciones de Occidente. 
Tradicionalmente, los museos han sido el producto de una actividad coleccionista y su existencia ha quedado justificada por su estrecha vinculación con la colección de objetos en torno a la cual giraba una institución encargada de tutelar y conservar los testimonios que configuraban la cultura material de una comunidad social, desechando cualquier otro tipo de actividad. Como afirmó Aurora León (1982), «el coleccionismo, pese a sus graves taras, era un fenómeno sociocultural necesario para que apareciese la institución museística» (p. 67). Tanto es así que la concepción y la organización de los museos han sido durante centurias «resultantes empíricas de una práctica acumulativa de experiencias en el tiempo, siempre consecuentes con el contexto político, socioeconómico y por ende cultural, de determinados grupos sociales poseedores de objetos museables» (Linares, 1994, p. 17).

Sin embargo, existen notas particulares que distinguen la situación y la morfología de los museos en el siglo XX, de aquellas que propiciaron en el siglo XIX su configuración moderna y entre las que destacan, según Zubiaur (1999), dos experiencias de tipo renovador que permitieron a la institución pasar de ser estática a ser dinámica:

1) $\mathrm{Su}$ proyección sobre el entorno social: mediante planes de promoción sociocultural dirigidos a la comunidad, tendentes a la superación de marginaciones sociales y culturales.

2) La intensificación de las relaciones público-museo a través de distintas acciones que involucraron todo tipo de personas y organismos de una comunidad como, por ejemplo, las asocia- ciones de amigos de los museos, los servicios de préstamo, la organización de actividades entre distintas entidades colaboradoras y el servicio de voluntariado, entre otros.

De ellas ha dependido que en la actualidad el museo no se limite únicamente a las tradicionales funciones de conservación, investigación, exhibición, adquisición y comunicación, sino que haya adquirido una mayor dimensión social dentro del proceso de expansión que afectó a la institución museística a partir de los años setenta (Alonso, 1993) (Figura 1).

Sin duda, la posguerra propició espectaculares cambios y una larga etapa de crecimiento y renovación del museo, pues en el período de reconstrucción material, sociológica y también psicológica que siguió a la contienda los espacios museísticos vivieron un auténtico renacimiento a nivel conceptual, material, legal y organizativo (Alonso, 1993).

Principalmente por el despliegue que Europa acometió para la protección de la cultura en todas sus vertientes, ésta se convirtió en el principal recurso que cada comunidad humana tenía para transmitir a las generaciones venideras la autenticidad de su identidad. El protagonismo de la cultura como rasgo colectivo era la respuesta a un despertar de la conciencia social que conectó vehementemente territorio, museo y sociedad. Un fenómeno que se explica a través de una «interrelación dialéctica entre cultura, identidad y patrimonio» (Alonso, 1993, p. 78).

Los parámetros que habían determinado el concepto de patrimonio histórico-artístico se ampliaron y se pasó a valorar todo un conjunto

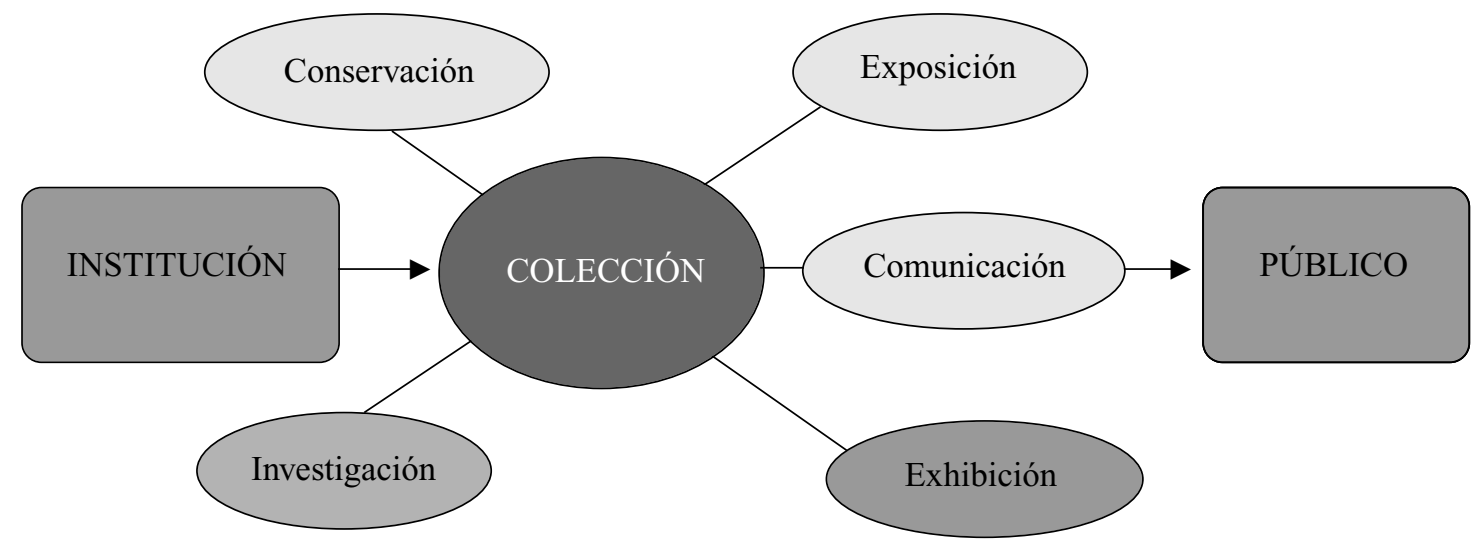

Figura 1. Las funciones tradicionales del museo, según el ICOM.

Elaboración: Luz M $\mathrm{M}^{\mathrm{a}}$ Gilabert. 
de tipologías «exponentes de civilización», que, por su carácter social, por su valor para la identidad cultural o por su función de destino público eran dignas de ser protegidas. La nueva definición de patrimonio cultural reunió en un mismo término todos los bienes muebles e inmuebles, materiales e inmateriales, de propiedad de particulares o de instituciones $\mathrm{u}$ organismos públicos o semipúblicos, que tenían un valor excepcional (González, 1999).

La aparición de ese nuevo concepto supuso el incremento de los testimonios a ser custodiados por los museos, a medida que estas instituciones eran consideradas como los principales guardianes de la memoria cultural (Brown, 1999). Otra de las consecuencias fue el extraordinario aumento en número y en diversidad de tipologías que enriquecieron el contexto museológico para dar cabida a dicho patrimonio. Surgen entonces los ecomuseos, los museos integrales y los museos polinucleados (en el territorio portugués) con la finalidad de conectar las colecciones y la temática del museo con el medio natural y social de la comunidad donde se asientan (Romero de Tejada y Picatoste, 2002).

A esto se sumó el nacimiento de organizaciones nacionales e internacionales dedicadas a la cultura y a los museos, como fueron los casos de la United Nations Educations, Scientific and Cultural Organization (UNESCO) y el International Council of Museums ( ICOM), ambos en 1946. Se estima que más del 70 por ciento de los museos actuales fueron constituidos tras la formación del Consejo internacional de museos, y por citar algunos datos concretos, en el Reino Unido, de los 1.677 museos y galerías de arte existentes en 1996, más de la mitad se fundaron a partir de 1945 (Bailey, Falconer, Foley, Mcpherson y Graham, 1998).

Una vez conseguida la estabilidad política y el nacimiento de los estados democráticos, el ICOM celebró su IX Conferencia General, en Grenoble y en París, con el tema: Le musée au servicie des hommes aujord'hui et demain. De ella emanó una nueva definición de la entidad museística que pasó a ser una institución permanente, sin finalidad lucrativa, al servicio de la sociedad y de su desarrollo. A partir de ese momento los museos van a definirse por su vocación de servicio a la comunidad.

En realidad, era un enunciado más acorde con las circunstancias históricas que se estaban viviendo y donde el valor social de la organización, y por lo tanto, del visitante alcanzaban una mayor significación. Así a las tradicionales funciones de salvaguarda y protección del patrimonio cultural, se añadió un nuevo cometido social.

Desde otra visión, se observa una intensificación de la labor divulgativa de los centros que fue el reflejo de los ideales defendidos por la nouvelle muséologie o nueva museología. Una corriente de pensamiento, vinculada a la revolución tecnológica y al aprendizaje experimental de finales de siglo, que convierte a los museos en espacios activos y donde lo importante es transmitir el contenido del mensaje más que los objetos propiamente dichos. Los guías como los voluntarios empiezan a adquirir un mayor protagonismo en la visita a los museos. La interacción entre el visitante y el personal va a ofrecer una experiencia mucho más intensa y enriquecedora dentro de la institución ya que los conocimientos que aportan al público sobrepasan los objetos y los contenidos, permitiendo un encuentro mucho más atractivo y fructífero; casi inexplicable con palabras.

Y es que en palabras del filósofo italiano, Remo Bodei (1996), «el ámbito de la memoria -individual o colectiva - no representa nunca un terreno neutral, sino un auténtico campo de batalla, en el que se decide, se perfila y se legitima la identidad de un pueblo o de una cultura» (p. 25). Esta identificación de la memoria como parte identitaria de la sociedad sigue repercutiendo en la misión del museo en el siglo XXI. La globalización, como nuevo contexto, ha ensalzado una fuerza social que defiende lo propio, las raíces y la diversidad cultural de los pueblos. Según Scheiner (2008), la globalización hace emerger movimientos que exacerban las características, deseos y reivindicaciones específicos de cada colectividad.

Waters (2001), al referirse a la globalización, se concentra en la relación entre la organización social y la territorialidad. Esta relación viene determinada por los tipos de intercambio que predominan los tres dominios de la vida social (economía, política y cultura).

La cultura implica la producción, el intercambio y la expresión de símbolos que representan afectos, significados, creencias, preferencias, gustos y valores que van más allá de los espacios, es decir, del territorio. Según el autor, los símbolos pueden ser creados en cualquier lugar y en 


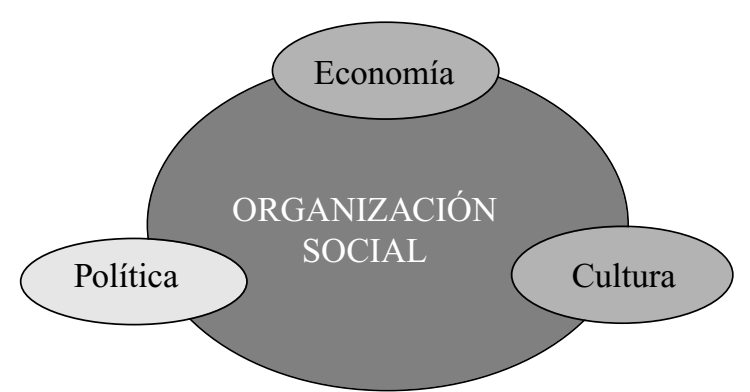

Figura 2. Los tres dominios de la vida social. segùn Waters (2001).

Elaboración: Luz $M^{a}$ Guilabert.

cualquier momento por eso son intercambios que globalizan, que siempre unen a la sociedad humana más allá del espacio y el tiempo. Nos habla, en realidad de que la cultura es una red simbólica de relaciones que, cuando se valora debidamente, contribuye a la dignidad humana y al ejercicio comunitario pues es el lazo y el vehículo que une una generación a otra (Figura 2).

El museo ha sido siempre y será un magnífico espacio para el intercambio de símbolos, la sociabilidad y la convivencia ciudadana. Una muestra de ello es el trabajo que realizan las personas mayores de forma voluntaria como guías dentro de dicha institución. A través de ellos no sólo se intercambian y se conectan símbolos, sino que además se produce una conexión intergeneracional plagada de experiencias humanas y con la que se mejora la calidad de vida de estos voluntarios. Gracias a esas visitas guiadas se facilitan sus posibilidades de desarrollo personal de una forma integral a través de la práctica cultural.

Desde esta perspectiva, la Federación de ecomuseos y museos de sociedad (FEMS) en Francia propone una lectura de los museos en términos de verdaderos espacios de intermediación, interculturales e intergeneracionales, al servicio de poblaciones plurales en búsqueda de referencias (Zulaika, 2009). Es por esa razón que «la dinámica de las distintas expectativas que tiene la población con relación a los museos hace de esta institución una de las más complejas de las creadas por el ser humano, presente en su diversidad en más de ciento setenta países» (Nascimento Junior, 2008, p. 20).

Por ello, analizar el museo y todos sus agentes debe hacerse como si se tratara de un ente vivo y dinámico en constante cambio y movimiento y lleno de relaciones sociales e interpersonales.
En él se descubre la verdadera esencia de la cultura y la memoria de los pueblos: objetos, contenidos de la identidad e intercambio con personas que los visitan y otros, como las personas mayores, que los enseñan de manera altruista, aportando ideas y argumentaciones que enriquecen el discurso tradicional y convencional de los museos. Veamos a continuación cómo y por qué surge concretamente este tipo de iniciativa en los museos de España.

\section{El Voluntariado cultural de mayores. Una experiencia consolidada en nuestro territorio} Desde 1993, en nuestro país, la Confederación española de aulas de tercera edad (CEATE) viene desarrollando hasta la actualidad un programa de «Voluntarios Culturales Mayores para enseñar los museos y catedrales de España a niños, jóvenes y jubilados». Más de mil voluntarios, mayores de 50 años de edad, en su mayor parte jubilados y pensionistas se ocupan de enseñar este patrimonio de forma altruista y desinteresada en más de un centenar de museos de España y algunas catedrales, iglesias, ermitas, el Jardín botánico de Madrid y otras instituciones culturales (ayuntamientos, bibliotecas, archivos, etc.).

Este ambicioso e innovador programa, que nació con motivo de celebrarse en 1993 el «Año europeo de las personas mayores y de la solidaridad intergeneracional», desde sus inicios contó en España con el apoyo económico de la Unión Europea y, posteriormente, del Ministerio de Cultura y del propio IMSERSO, viéndose en todo momento arropado por la Federación española de amigos de los museos (FEAM) y diversas organizaciones de personas mayores. Por su enorme repercusión cultural y social ha recibido el «Premio Extraordinario del IMSERSO 1998», el Premio nacional Júbilo 2000 y múltiples felicitaciones de las más altas instancias del Estado, de las Administraciones Públicas y de muchos directores de museos.

Este programa de "Voluntariado cultural de museos» se fundamenta en la necesidad de aprovechar el potencial humano, los conocimientos y las experiencias de personas de 50 años en adelante, en su mayor parte jubilados y pensionistas, con mayores niveles educativos y culturales, con mejor salud y bienestar, con deseos de seguir activos, participativos y útiles a la sociedad, con mucho tiempo libre disponible, auténticas «bibliotecas ambulantes», que desean trasmitir la cultura, el ar- 
te, la historia y la ciencia que se encierran en los Museos y en el patrimonio artístico español. Y no sólo a los niños y jóvenes estudiantes, en un fructífero encuentro intergeneracional, sino también a aquellos colectivos sociales tradicionalmente marginados del disfrute de los bienes culturales como son, personas con disminución, emigrantes, minorías étnicas y los propios jubilados.

Por su parte, este programa viene a llenar un vacío, una necesidad de muchos museos españoles que no cuentan con este servicio, mientras que, al mismo tiempo, ayuda de forma eficaz a dar a conocer y potenciar los mismos museos, aumentando el número de sus visitantes individuales y grupales.

Los aspirantes a convertirse en voluntarios de los museos, en primer lugar reciben un curso sobre «Voluntariado cultural, personas mayores y museos» de cuatro días de duración y, posteriormente, son destinados al museo que cada voluntario elige con el fin de recibir la formación adecuada en las materias y contenidos del mismo por parte del director, o de los conservadores y técnicos. Esta formación dura dos o tres meses aproximadamente, dependiendo de la biografía personal de los candidatos a convertirse en voluntarios culturales.

Finalmente, cuando el director o la persona del museo en quien delega la responsabilidad de la capacitación, el seguimiento y la coordinación del «equipo» de voluntarios mayores, considera que ya están formados para una enseñanza rigurosa y de calidad de la exposición permanente del museo, los voluntarios mayores pasan a enseñar y a transmitir toda la riqueza cultural, histórica, artística y científica que se muestra en sus salas y vitrinas a los niños y jóvenes estudiantes $\mathrm{y}$ a todos aquellos grupos que se acercan a visitarlos. Es en este momento, y no antes, cuando CEATE les considera «voluntarios culturales de pleno derecho» y le proporciona a cada uno la tarjeta de acreditación ante terceros (personal del propio museo y público visitante), la misma en todos los museos integrados en el programa.

Los gastos de impresión de los trípticos informativos, carteles y tarjetas de acreditación, así como de una póliza de seguros por accidentes corren por cuenta de la Confederación con cargo a la ayuda económica que recibe de las obras sociales. El museo cuenta, por lo tanto con unas personas mayores, maravillosas, atentas, motivadas, bien preparadas y esforzadas, que, de manera altruista, se entregan a enseñar el museo a los grupos de visitantes.

Más de 1.200 personas mayores han disfrutado ya con esta tarea, se sienten felices de poder seguir activos y útiles a la sociedad, aumentan su autoestima, bienestar, salud y calidad de vida.

Y más de tres millones de niños y jóvenes estudiantes han disfrutado ya, y será aún mayor en próximos años, con las enseñanzas de estos modernos cicerones mayores que va creciendo año tras año.

\section{La pedagogía de la experiencia. La «gene- ratividad» como elemento vital}

Esta capacidad de las personas mayores de producir servicios útiles para el resto de la comunidad fue denominada por el autor Erickson (1982) «generatividad». La «generatividad», en la última etapa del ciclo vital de la persona, proporciona una implicación en la vida cívica y social, con un papel inminentemente intergeneracional. El papel de la «generatividad» sitúa a la persona mayor en el concepto de envejecimiento productivo, enfatizando las contribuciones de las personas mayores al bien común y aportando su actividad como un sentimiento de «capital social». Según Putnam, Leonardi y Nanetti (1993)

[Capital social] Activo históricamente acumulado para una sociedad a partir de la acción organizada de sus miembros - a nivel individual o colectivo- - sobre la base de determinadas normas sociales de cooperación, la interiorización de diversos valores - confianza, solidaridad, reciprocidad - y la existencia de un tejido social o red de compromiso que permite una mejor eficacia en la consecución del bienestar.

O también como podemos rescatar del autor Coleman (1988; 1990), que considera el capital social como un compendio de recursos, redes sociales - los lazos de parentesco, las redes comunitarias informales, las organizaciones sociales, que permiten obtener beneficios en forma de flujos de solidaridad, capacidad de defensa de intereses y derechos, obtención de información-, las normas sociales - de voluntariedad, altruismo, comportamiento- y los vínculos de confianza social que garantizan un entramado de obligaciones y expectativas recíprocas que posibilitan la cooperación.

El concepto de «generatividad» plantea la pregunta fundamental para la persona mayor y 
que se plantea como: ¿Qué puedo seguir aportando a la sociedad? y moviliza virtudes, actitudes y procedimientos en la persona que permiten una participación social y comunitaria. La persona mayor se plantea la actividad de la «generatividad» como un asegurar el bienestar a las generaciones futuras, y en último lugar, dejar un legado que pueda sobrevivir a su itinerario vital.

Algunos autores, como Villar (2012), visualizan esta aproximación como muy positiva del buen envejecer de la persona en nuestra sociedad tecno-científica, donde se pretende reconocer y hacer visibles las aportaciones de los mayores a la sociedad, asumiendo que no son un estorbo o un colectivo improductivo -como muchos nos hacen creer- y que pueden contribuir de forma pedagógica al bien común, siendo una parte esencial en el funcionamiento y engranaje social; de esta forma, el concepto de poder «hacer alguna cosa útil», convierte el envejecimiento productivo en una perspectiva real y diferente al envejecimiento activo ${ }^{1}$.

Hablar del concepto de «generatividad», en primer lugar, permite un desarrollo social y comunitario ya que dichas actividades se orientan a la atención, mantenimiento y mejora tanto de las personas con quien se relacionan como de las instituciones donde participan; y en segundo lugar, tenemos que hablar del desarrollo individual, ya que las personas encuentran significado a sus vidas y son capaces de capacitarse a partir de procesos educativos - como se ha podido demostrar en las formaciones recibidas para poder explicar el arte del museo-y así poder ejercer nuevos roles socialmente significativos, potenciando sus propias competencias, habilidades e intereses que amplían el abanico de actividades generativas posibles.

Descubrir la potencialidad de dichos escenarios nos permite trazar dos futuros caminos de Trabajo Social: uno que es individual, centrándose en las capacidades de la persona y la socialcomunitaria, modificando los contextos de participación para abrirlos a las contribuciones de los mayores y favoreciendo que puedan implicarse. Como afirma el pedagogo Dewey (1995): «una sociedad indeseable es aquella que pone barreras internas y externas al libre intercambio y comunicación de la experiencia. Una sociedad es democrática en la medida que facilita la participación en sus bienes a partir de sus miembros»».

En otras palabras: no tratamos de «dar» a las personas mayores nada. Absolutamente nada. Lo que buscamos y queremos es que puedan «poner sobre la mesa» sus capacidades, conocimientos y potencialidades — que las tienen-, siendo el eje central de la experiencia. Y por lo tanto dichas actuaciones permiten superar los obstáculos de la vida, desarrollándose como individuos y participando en grupos sociales en la comunidad.

Como dirían Tobío, Agulló, Gómez y Martín (2010):

El envejecimiento en nuestra sociedad no es sólo una expresión de moda o una propuesta de vanguardia. Constituye un reto y una realidad constatable. Si bien una tercera parte de las personas mayores son independientes, las aportaciones del otro $70 \%$ merecen ser destacadas. Esto implica que los mayores van más allá de la reciprocidad: generalmente dan más de lo que reciben, ya sea en un contexto familiar o extrafamiliar. Sus aportaciones puede ser psicosociales o sociológicas, maestros de vida, asesores en cuestiones técnicas, soporte a la atención de personas, con capacidad cultural».

Dar valor a las personas mayores es reconocer su contribución y su potencial.

\section{EI Trabajo Social y la «generatividad» co- mo elementos de trabajo conjunto}

El Trabajo Social en la «generatividad» se puede definir como el desarrollo de la comunidad por medio de los recursos y las potencialidades de la persona mayor. La «generatividad» nos plantea el Trabajo Social mediante un modelo de intervención participativo, es decir, partiendo de la participación implicada del individuo en la red social y en el territorio. Se aleja, por lo tanto, de una participación planteada desde los parámetros de la beneficencia y el asistencialismo o a través de unos modelos de intervención más tecnocráticos.

${ }^{1}$ Robert N. Butler i Malvin Schechter (1995), definieron el envejecimiento productivo como «la capacidad de un individuo o de una población para servir en la fuerza del trabajo remunerada, en actividades de voluntariado, ayudar dentro de la familia y mantenerse el máximo de independiente posible» (p. 763). En cambio el envejecimiento activo, definido por la ONU (2002) es «el proceso de optimizar las oportunidades de salud, participación y seguridad para promover la calidad de vida a medida que se envejece». 
Debemos, sin embargo, plantear los procesos de «generatividad» como piezas del engranaje que permiten una interacción globalizadora $\mathrm{y}$ complementaria entre los diferentes modelos de intervención consiguiendo ampliar la concepción de desarrollo comunitario establecido.

Recordemos que, según el Instituto de Desarrollo Comunitario (IDC), «el desarrollo comunitario significa un proceso de transformación y mejora de las condiciones de vida y trabajo de una comunidad, tomado a su cargo y materializado por la propia comunidad.»

El concepto de proceso, por lo tanto, es importante en la conceptualización de la «generatividad» en las personas mayores, ya que interviene para alcanzar el desarrollo en la comunidad. Proceso que plantea un cambio, una mejora desde la propia comunidad. Este desarrollo exige, por lo tanto, para los trabajadores sociales la posibilidad de plantear dinámicas mediante «la participación, la adquisición de nuevos conocimientos, el ejercicio de la responsabilidad y la iniciativa» y a su vez se puede fundamentar desde una dimensión teórica (Imagen 2).

En el desarrollo comunitario, corresponde al Trabajo Social alimentar un proceso que facilite que las personas mayores o los grupos de mayores se pongan en marcha o sean agentes del propio desarrollo, trabajando para facilitar a la comunidad el desarrollo de los propios recursos, del tejido social o comunitario, para superar carencias y facilitar el crecimiento en todos los sentidos. Tal y como indica Jaraíz (2012), a nadie se le escapa que este nuevo escenario, más complejo, obliga al agente de Servicios Sociales

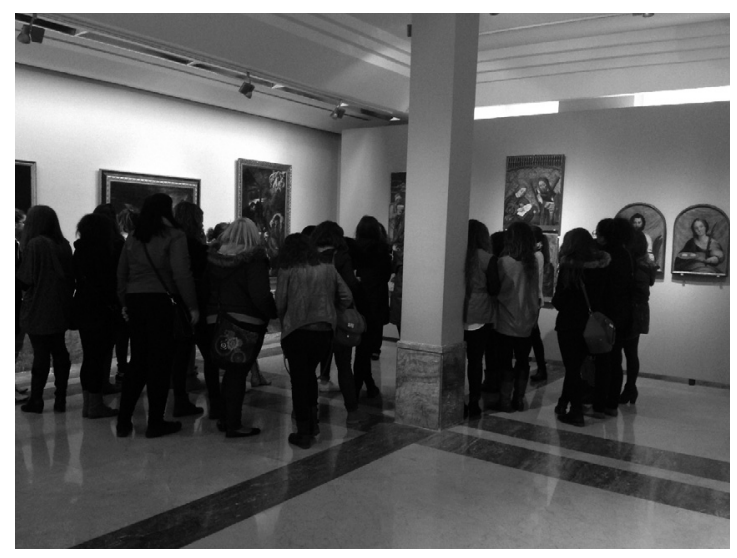

Imagen 2. El voluntariado intergeneracional en el museo.

Foto: Luz Ma Gilabert. comunitarios a resituar sus formas de presencia, su acción.

Por otro lado, debe trabajar con el individuo como unidad implicada en la red social. El aprendizaje es un proceso que tiene lugar a lo largo de toda la vida. En este sentido, debemos considerar un trabajo educativo desde la perspectiva de la educación permanente que se da, por un lado, en la educación de adultos no entendida como una formación compensatoria (alfabetización) sino de modo más integral de la persona $\mathrm{y}$, al mismo tiempo, de desarrollo comunitario y social. La educación, vista así, se fundamenta en el concepto de Paulo Freire (1997), según el cual «educar es un método de concienciación que busca la emancipación social y cultural más que la transmisión de conocimientos»).

Desde esta óptica, la intervención del Trabajo Social en los estadios de «generatividad de esta conceptualización filosófica de la intervención, se plantea a través de los agentes culturales (la persona, el grupo, la comunidad) mediante las potencialidades personales, con la capacidad creativa, la participación, la democracia cultural y al mismo tiempo incidiendo en la comunidad, en la sociedad que es cambiante, planteando la intervención por las personas, en un territorio. Este planteamiento conlleva intervenir con las personas y con el territorio de forma real.

Recordemos algunos instrumentos que podemos encontrar desde esta perspectiva:

a) Actividades de planificación, organización y gestión, con las que el trabajador social tiene que ser capaz de facilitar las estrategias y los recursos necesarios para que la comunidad pueda desarrollarse con las capacidades propias. Planificar los medios posibilita que los procesos educativos, sociales y culturales trabajados mediante la dinamización sean una realidad.

b) Actividades, técnicas de grupo, intervención grupal y recursos técnicos son herramientas que, en la vertiente psicológica, tienen incidencia en la participación de los individuos, de las asociaciones y de la comunidad. El trabajador social debe estar formado para llevar a cabo dinámicas de grupo y estrategias que incidan en la motivación de la persona para ser activa a partir de su propia autonomía personal.

c) La investigación social es otro instrumento importantísimo, ya que nos permite conocer, 
investigar, profundizar en las claves que nos posibiliten cambios actitudinales, de valores, de concepto respecto a la persona y a la sociedad en que vive. Investigar supone conocer y hallar respuestas a las situaciones que se van dando.

d) Los medios de comunicación social personales propios del trabajador social, con sus límites y sus potencialidades forjados a partir del autoconocimiento de las posibilidades personales y del rol asignado en la propia intervención; de grupo, con las posibilidades que comporta el trabajo en equipo, el trabajo del conflicto con el consenso. El grupo permite la identificación, el sentimiento de pertenecer, el hecho de intervenir al lado de..., colaborando con... En último término, en los medios de comunicación de masas en los que el Trabajo Social debe estar presente para sensibilizar sobre las problemáticas concretas $y$, si es necesario, denunciar las situaciones que atenten contra la dignidad humana y que eludan los planteamientos éticos de la profesión.

Y por último, los programas de acción de la «generatividad» en el Trabajo Social:

a) La participación. La persona mayor debe ser el sujeto del propio proceso, el protagonista. Si no partimos de la persona mayor y su «generatividad» crearemos dinámicas basadas en el estereotipo y en los tópicos, como la distracción o el hecho de atribuir unos tipos de actividades determinadas a cada ámbito.

b) La dimensión comunitaria que da importancia a la vertiente colectiva, a la integración, a la socialización, al sentimiento de pertenencia, a la construcción social partiendo de la dimensión personal. La comunidad basada en el diálogo entre las opciones de las personas que crean redes humanas con sus capacidades y potencialidades individuales. Mejorando las relaciones intergeneracionales.

c) El sentido globalizador que implica trabajar desde la persona, considerándola como un todo en el que se complementan la cultura, la educación y las habilidades sociales que la conforman como tal. Se trabaja para la socialización de la persona en un proyecto común capaz de responsabilizar, generar hábitos, promover respeto (valores educativos) en la interrelación comunicativa que configura la cultura de una comunidad.

d) La orientación hacia el cambio. El desarrollo comunitario plantea unos objetivos más o menos utópicos, relacionados con la creación y el cambio o transformación de la realidad. Esta orientación transformadora debe ser capaz de generar cambios para el desarrollo de la sociedad, de una sociedad fundamentada en la democracia cultural y en la realización personal y colectiva.

\section{Transformación de la realidad a principios del siglo XXI}

El año 2007 fue el Año Europeo de la Igualdad de oportunidades para todos. Una oportunidad para poner el foco de atención en el lugar que ocupan las personas mayores en nuestra sociedad y dar paso a trabajos de sensibilización de la población en cuanto a la igualdad y la lucha contra los prejuicios. Según McCashen (2005), la idea fundamental de la perspectiva del fortalecimiento es la de alejar el foco de atención en los déficits y centrarla en las fortalezas y los recursos, para dar lugar a la construcción de las competencias que facilitan el cambio y limitan o eliminan las conductas disfuncionales. La tercera y cuarta edades forman parte del ciclo vital de los seres humanos. El sistema de solidaridad institucional que hemos creado ha llevado a proporcionar servicios especializados de alta calidad, pero también ha dado lugar a una descomposición progresiva de la solidaridad horizontal o de proximidad. Este hecho, en coacción con unos valores imperantes que veneran la juventud y la productividad, de alguna manera, tienden a apartar, a las personas mayores de la vida activa de la sociedad. Para muchos actores de nuestra sociedad, el interés que pueden suscitar las personas mayores radica tan sólo en el papel de consumidores pasivos.

Las personas mayores, en tanto que personas con un largo ciclo de vida, poseen una riqueza no (o no solo) material sino sobre todo de experiencia, de conocimiento, de cultura y de tiempo libre. El aporte que dan y pueden dar a la sociedad debe ser revalorizado. Así es como se ha introducido cada vez más en dicho colectivo, el concepto de empowerment ${ }^{2}$. El empowerment,

${ }^{2}$ Este término aparece en la definición del Trabajo Social, tanto desde la Asociación Internacional de Escuelas de Trabajo Social (IASSW) como desde la Federación Internacional de Trabajo Social (IFSW). 
tal y como nos lo recuerda la autora (Segado, 2011) está directamente relacionado con el poder y la forma en la que se distribuye entre las personas. Los actuales acontecimientos sociales vividos en nuestro tiempo (crisis económica, cambio demográfico, desplazamiento de personas refugiadas en otros países, etc.) están permitiendo que la sociedad en su conjunto dirija una nueva mirada a toda la riqueza que el potencial humano, clasificado en las categorías de tercera y cuarta edad, pueden aportar. Una oportunidad para que revaloricemos y readaptemos viejos valores de solidaridad, de compartir, de riqueza intergeneracional y de convivencia.

Los servicios sociales, sanitarios y sociosanitarios deben tener en cuenta, cada vez más, la importancia no tan sólo del estado de autonomía o dependencia y salud de la persona mayor sino su voluntad de vivir, y animarle que sea partícipe de la sociedad manteniendo y aportando los conocimientos y actividades que la persona desee y ame. Participar en la vida activa de la sociedad no es tan sólo producir o consumir.

No deberíamos olvidar la Declaración Ministerial de León: Una sociedad para todas las edades: retos y oportunidades de la Comisión Económica para Europa (CEPE) que se celebró en España (León, 6-8 de noviembre de 2007) y donde ya se anunció cómo debemos actuar para poder lograr un proceso participativo de la sociedad civil «de abajo hacia arriba». Muy pocas actuaciones sociales, están inmersas en conseguir ese objetivo.

Creemos que es importante también remarcar que buena parte del cambio deseado para conseguir un buen mantenimiento del sistema de protección social recae en la toma de conciencia y la actuación responsable de cada individuo de esta sociedad. Esto es una visión loable y esperanzadora que requerirá una fuerte inversión en el desarrollo de un sistema educativo que promocione el espíritu crítico, la dimensión de solidaridad horizontal y la conciencia de ser parte proactiva de la sociedad. Estas esferas de conocimientos se contradicen con la tendencia al individualismo que estamos viviendo hoy en día.

El sistema en el que vivimos ha institucionalizado la solidaridad para asegurar una cobertura de las necesidades básicas a toda la población, esto ha tenido efectos muy positivos para el conjunto de la población, pero también ha hecho que la solidaridad horizontal (de vecindad, de comu- nidad, familiar, etc.) quede desvirtuada y en desuso. Ahora vemos la necesidad de recuperarla con un nuevo contexto histórico y social. Esto implica también una trascendencia en el planteamiento de los sistemas sociales.

Vamos a vivir auténticas revoluciones en nuestro siglo XXI, una de ellas, la más cercana, la que conocemos por los datos demográficos -insistentes en nuestra vida cotidiana- será el envejecimiento de nuestra población $\mathrm{y}$, por defecto, la longevidad y el cambio en la estructura de las edades. En estas nuevas condiciones demográficas los vínculos familiares tienen una duración sin precedentes y permiten varias décadas de vida compartidas entre hermanos, padres e hijos, e inclusive entre abuelos y nietos. El papel, por lo tanto, del trabajador social es ejercer la práctica con las personas mayores desde la perspectiva del fortalecimiento que significa facilitar el descubrimiento, la exploración y el uso de las fortalezas y los recursos, con el fin de ayudarles a lograr sus objetivos. Y esto se debe tal y cómo indican los autores Hepworth, Rooney y Larsen (2002) a la persistencia de los trabajadores sociales en trabajar desde el modelo de la patología y la disfunción de los clientes. Sin embargo, con el paso del tiempo la disciplina del Trabajo Social está consiguiendo que los trabajadores adopten la perspectiva de las fortalezas, y no la de las debilidades. Los mayores son un ejemplo claro.

Recientes investigaciones relacionadas con nuevas formas de ver el envejecimiento han dado demostraciones contundentes de que sin un arraigo o sentido de pertenencia social, no podemos aprovechar plenamente el potencial que ofrece la nueva longevidad (Pinazo, Lorente, Mendizábal, Bermejo, Prado, 2010). Es en los vínculos con los demás en donde podemos ver la conexión entre el comienzo y el final de la vida. En las interrelaciones humanas dónde podemos mantener un sentido de dominio y capacidad de funcionamiento. Si esta forma de comprender la vida se reflejara mejor en las políticas educativas $\mathrm{y}$ sociales, en general, las vidas de hombres y mujeres cambiarían dramáticamente, para mejor.

Este nuevo papel de los mayores, de cubrir no tan sólo sus necesidades, sino que también pueden ayudar al resto de generaciones - a partir de la transmisión del arte y de la cultura- es nueva por primera vez en nuestra historia socioeducativa y esta nueva situación los configura como un segmento de población a tener muy presentes 
en los procesos de enseñanza-aprendizaje futuros y por defecto, serán una parte activa de esta nueva realidad intergeneracional. Todo ello para proporcionar una mayor y mejor atención a las personas mayores y por defecto a la sociedad en general.

\section{Referencias bibliográficas}

Alonso Fernández, L. (1993). Museología. Introducción a la teoría y práctica del museo. Madrid: Istmo. Bailey, S., Falconer, P., Foley, M., Mcpherson, G. y Graham, M. (1998). Charging for Admission to Museums and Galleries: Arguments and Evidence. The International Journal of Museum Management and Curatorship, 16(4), 355-369.

Bermejo, L. (2010). (dir.) Envejecimiento Activo y Actividades Socioeducativas con Personas Mayores. Guía de Buenas Prácticas. Madrid: Editorial Panamericana.

Bodei, R. (1996). Tumulto de criaturas congeladas. O sobre la lógica de los museos. Revista de Occidente, 177, 21-34.

Brown, E. H. (1999). Los museos hoy. En Lo público y lo privado en la gestión de museos. Alternativas institucionales para la gestión de museos (pp. 19-40). Buenos Aires: Fondo de Cultura Económica de Argentina.

Butler, R. y Schechter, M. (1995). Productive Aging. En G.L. Maddox (ed.), The encyclopedia of aging (pp. 763-764). Nueva York: Springer.

CEPE. (2007). Declaración Ministerial de León. Madrid: IMSERSO.

Erikson, E. (1982). El ciclo vital completado. Buenos Aires: Paidós.

Freire, P. (1997). Pedagogía de la autonomía: saberes necesarios para la práctica educativa. Buenos Aires: Paz e Terra y Siglo XXI.

Gilabert González, L.M. (2014). Los museos municipales de Murcia: historia, política y gestión. Murcia: Editum.

Gilabert González, L.M. (en prensa). La gestión y organización de los museos en España y Portugal. Gijón: Trea.

Hepworth, D.H., Rooney, R.H. y Larsen, J. (2002). Direct social work practice: Theory and Skills. Pacific Grove: Brooks/Cole.

Jaraíz Arroyo, G. (2012). La dimensión comunitaria en Servicios Sociales. Una aproximación a su tratamiento en barrios vulnerables. Cuadernos de Trabajo Social, 25(1), 113-124.

León, A. (1982). El museo. Teoría, praxis y utopía (2a ed.). Madrid: Cátedra.

Linares, J. (1994). Museo, arquitectura y museografia. Madrid: Ediciones J.F.

McCashen, W. (2005). The Strengths approach: A strengths-based resource for sharing power and creating change. Victoria, Australia: St. Luke's Innovative Resources.

Nascimento Junior, J. do (2008). Los museos como agentes de cambio social y desarrollo. Museos.es: Revista de la Subdirección General de Museos Estatales, 4, 16-27.

Pinazo, S., Lorente, X., Mendizábal, M.R.L., Bermejo, L. y Prado, S.F. (2010). Envejecimiento y aprendizaje a lo largo de la vida. En L. Bermejo (dir.), Envejecimiento activo y actividades socioeducativas con personas mayores: guía de buenas prácticas (pp. 1-10). Madrid: Editorial Panamericana.

Romero de Tejada y Picatoste, P. (2002). Identidad cultural y museos. Una visión comparada. Revista Museo, 6, 1-13.

Scheiner, T. C. (2008). El mundo en las manos: museos y museología en la sociedad globalizada. Revista Cuicuilco, 15(44), 17-36.

Tobío, C., Agulló, M.S., Gómez, M.V. y Martín, M.T. (2010). El cuidado de las personas. Un reto para el siglo XXI. Barcelona: La Caixa.

Villar, F. (2012). Hacerse bien haciendo el bien: la contribución de la generatividad al estudio del buen envejecer. Información Psicológica, 19, 39-56.

Waters, M. (2001). Globalization (2 $2^{\mathrm{a}}$ ed.). Londres: Routledge.

Zubiaur Carreño, F.J. (1999). El museo al servicio de la memoria e identidad colectivas. Cuadernos de Etnología y Etnografia de Navarra, 73, 281-288.

Zulaika, R. (2009). Museos e integración. Revista Amigos de los Museos, 28, 16-19. 